\title{
MENSURAÇÃO DOS CUSTOS DE OPERAÇOES REVERSAS DE RECICLAGEM: ESTUDO DE CASO NUMA EMPRESA DO SETOR DE PLÁSTICO EM CAMPINA GRANDE-PB
}

\section{MEASUREMENT OF COSTS OF OPERATIONS REVERSAL OF RECYCLING: A CASE STUDY MADE IN A PLASTIC COMPANY IN CAMPINA GRANDE-PB.}

\author{
Júlio Cesar Ramos Loureiro Marinho ${ }^{1}$; Maria de Fátima Martins ${ }^{2}$ \\ ${ }^{1}$ Universidade Federal de Campina Grande - UFCG \\ julio13@ hotmail.com \\ ${ }^{2}$ Universidade Federal de Campina Grande - UFCG \\ fatimamartins@pq.cnpq.br
}

\begin{abstract}
Resumo
Em uma época que atitudes ambientalmente corretas são cada vez mais cobradas, práticas que diminuam a exploração aos recursos naturais são cada vez mais importantes. Nesse sentido, a logística reversa surge como alternativa para as empresas se diferenciarem no mercado, reduzindo seus custos, ao mesmo tempo em que se enquadram nas exigências legais e uma imagem positiva através de práticas sustentáveis. Nesse contexto, o artigo objetiva mensurar os custos do canal reverso de reciclagem, estabelecendo uma comparação com os custos do canal direto da fabricação de um produto numa empresa do setor de plástico em Campina Grande-PB. A pesquisa caracteriza-se como descritiva e exploratória por descrever o canal reverso de reciclagem da empresa e explorar um tema ainda pouco pesquisado, mediante análise qualitativa e quantitativa. Como método para mensurar os custos das atividades do canal reverso de reciclagem da empresa, tomou-se como base o modelo de Lima et al(2010), onde o mesmo utiliza o custeio ABC. Os resultados mostram que o canal reverso, mesmo apresentando alguns processos onerosos de recuperação do material, apresenta um menor custo para a empresa quando comparado com o canal direto com a utilização de matéria-prima virgem. Assim, a contribuição do presente estudo consiste em evidenciar que os canais reversos podem oferecer benefícios para as empresas através da redução de custos, ao mesmo tempo em que permite reduzir a utilização e exploração de recursos naturais, redução de impactos ambientais com a reciclagem, bem como, novas perspectivas econômicas para materiais considerados de baixo valor econômico.
\end{abstract}

Palavras-chave: logística reversa; reciclagem; redução de custos.

\section{Introdução}

O atual cenário econômico mundial mostra um mercado cada vez mais acirrado, com um nível de competitividade cada vez mais elevado e consumidores cada vez mais exigentes, onde empresas buscam atingir novos mercados e ao mesmo tempo se manter no mercado que está inserido. Na medida em que as indústrias de bens e serviços crescem, guiadas pelo avanço 
tecnológico, que possibilita a criação de novos produtos num intervalo de tempo cada vez menor e gera uma quantidade maior de resíduos obsoletos e descartáveis, cresce também a preocupação acerca dos impactos que esse aumento de resíduos vem causando e ainda causará ao meio ambiente e consequentemente a qualidade de vida da população.

A partir daí ficou eminente a necessidade da criação de um novo modelo de gestão que desse ênfase às questões ambientais e sociais, além das econômicas, tendo ciência que as organizações produtivas e de serviços possuem atividades que podem ser nocivas ao ambiente em que vivemos (PEREIRA et al, 2011). Modelo esse que enxergasse com racionalidade e consciência o planejamento e controle do fluxo de materiais e produtos desde a seleção da matéria-prima até a chegada do produto finalizado ao consumidor.

Nas últimas décadas o tema "logística empresarial" vem ganhando cada vez mais visibilidade no meio empresarial. Segundo Ballou (1995) a logística empresarial refere-se a todas as tarefas de movimentação e armazenagem que direcionam o fluxo de produtos e informações desde o fornecedor até o ponto de consumo final.

Por isso, a logística se tornou fundamental para uma empresa obter sucesso dentro do seu segmento, fazendo jus ao antigo conceito de ter o produto certo, na hora certa e na quantidade certa, tudo isso com o menor custo possível. Apesar de a logística ser bastante dinâmica, se limitava a canais de distribuição diretos, ou seja, quando o produto chegava ao consumidor final, teoricamente encerrava-se seu papel na cadeia.

Faltava para a logística uma área de atuação que abordassem também os canais reversos, fazendo com que os produtos (resíduos) já utilizados fossem inseridos novamente ao ciclo produtivo, estendendo sua vida útil, sendo reutilizados ou reaproveitando seus componentes. Assim surge a logística reversa e os estudos acerca dos canais de distribuição reversos. Chaves e Alcântara (2010) definem logística reversa como a atividade responsável pelo planejamento e gerenciamento do fluxo reverso de produtos vindos do consumidor até o ponto de origem, ou seja, produtos ou seus componentes que são recolocados em suas respectivas indústrias de origem ou em outro processo produtivo, para serem reutilizados na fabricação de novos produtos, ou também sendo comercializados de forma direta para o mercado de segunda mão, ou seja, readquirindo valor de alguma maneira.

Leite (2009) considera que são duas categorias de canais de distribuição reversos, definidas como de pós-venda e de pós-consumo. Logística de pós-venda atua com produtos com pouco ou nenhum uso, os casos mais comuns em que ocorre são relacionados a defeitos, erros na emissão do pedido ou simplesmente insatisfação do cliente, esse último bastante visto no e-commerce. Já a logística de pós-consumo é formada por produtos, peças e materiais constituintes cujo prazo de vida 
útil chegou ao fim, sendo assim considerados impróprios para serem comercializados em canais tradicionais de vendas.

As economias com a utilização de embalagens retornáveis ou com reaproveitamento de materiais para produção têm trazido ganhos que estimulam cada vez mais novas iniciativas (LACERDA, 2009). Nesse sentido, empresas estão sendo atraídas pela possibilidade de redução de custos através dos canais reversos, tendo em vista a aquisição de matérias primas recicladas que possuem preços inferiores as matérias primas virgens compradas a fornecedores diretos, o que incentiva cada vez mais essa prática em diversos setores.

A indústria de transformação do material plástico é de essencial importância para a economia nacional, pois abastece setores estratégicos da indústria brasileira como, por exemplo: alimentos e bebidas, automóveis/autopeças, construção civil, eletrônicos, instrumentos de saúde, entre outros. De acordo com a Associação Brasileira da Indústria do Plástico (ABIPLAST, 2011) o número de empresas no setor de transformados de plástico no Brasil era de 11.524 no ano de 2010, sendo as regiões sudeste e sul as que mais concentram essas empresas, tendo o nordeste em terceiro, seguidos por centro-oeste e norte. Em 2011, este setor foi responsável por mais de 350.000 empregos, ou cerca de 5\% do total de empregos na indústria de transformação brasileira. Ainda de acordo com a (ABIPLAST, 2011), o faturamento nacional deste setor girou em torno de 55 bilhões no ano de 2011. Na região nordeste existe cerca de 1000 empresas, sendo uma fatia de 9,5\% da indústria de transformados plásticos brasileira, tendo o Estado da Paraíba como o quarto estado com o maior número de empresas, cerca de 110, gerando aproximadamente 3.800 empregos, ficando atrás apenas dos estados da Bahia, Pernambuco e Ceará.

O plástico, por está presente em significativa parte dos segmentos da indústria de transformação, e por ser gerador de um alto número de resíduos de diferentes formas, tamanhos e composições químicas, e também por seu fácil uso e descarte, necessita de uma atenção especial no que diz respeito à destinação desses resíduos, tornando-se um desafio para indústrias, órgãos governamentais e para toda população em geral. Por todas essas informações citadas, a logística reversa vem sendo considerada uma importante ferramenta na diminuição de desperdícios, do impacto desses resíduos no meio ambiente e na conscientização da população acerca da importância da reciclagem e reutilização, e também dos ganhos econômicos conseguidos com a sua aplicação eficaz, tendo a logística reversa como oportunidade de redução de custos e maximização dos lucros, fator motivador de toda e qualquer empresa.

Nessa perspectiva, o objetivo do presente artigo consiste em mensurar os custos do canal reverso de reciclagem, estabelecendo uma comparação com os custos do canal direto da fabricação de um produto numa empresa do setor de plástico em Campina Grande-PB. A relevância do estudo consiste em evidenciar os benefícios da utilização dos canais reversos de reciclagem para redução 
de custos, com benefícios para o meio ambiente, a sociedade e os clientes, através da redução dos impactos ambientais e o acesso a produtos com preços mais competitivos.

Além dessa parte introdutória, o artigo apresenta uma seção com o embasamento teórico referente à temática logística reversa, logística reversa como alternativa para redução de custos, o método de custeio $\mathrm{ABC}$ e o setor de plástico, em seguida são apresentados os aspectos metodológicos, os resultados com a mensuração dos custos na empresa em estudo e, por fim, as considerações finais e as referências bibliográficas.

\section{Logística reversa}

A logística é uma área de atuação relativamente nova no meio empresarial, apesar de muitas empresas já a praticarem de forma inconsciente há bastante tempo. Conforme Bowersox e Closs (2011), a logística envolve a integração de informações, transporte, estoque, armazenamento, manuseio de materiais e embalagem. De acordo com o Council of Supply Chain Management Professionals a logística é a parte do gerenciamento da cadeia de abastecimento que planeja, implementa e controla o fluxo e armazenamento eficiente e econômico de matérias-primas, matérias semiacabados e produtos acabados, bem como as informações a eles relativas, desde o ponto de origem até o ponto de consumo, com propósito de atender exigências dos clientes.

Dessa forma, a missão da logística é dispor à mercadoria ou o serviço certo, no lugar certo, no tempo certo e nas condições desejadas, ao mesmo tempo em que fornece a maior contribuição à empresa (BALLOU, 2001), a partir de um desempenho integrado (BOWERSOX e CLOSS, 2011). Assim, a logística é um processo que deve ser pensado para potencializar o nível de serviço para o cliente final, no menor custo possível, tornando-se assim, essencial para a estratégia competitiva de qualquer empresa.

Uma área com crescente interesse dentro da logística empresarial é a logística reversa, que diferente dos canais diretos que partem da aquisição da matéria-prima até a entrega do produto ao cliente final, a logística reversa segue o fluxo inverso, recebendo produtos, embalagens ou materiais advindos do cliente final, fazendo com que retornem ao ciclo produtivo, estendendo assim o ciclo de vida do produto.

É importante ressaltar que a logística reversa apresenta um conceito ainda em evolução, tendo em vista as novas possibilidades de negócios relacionados com o interesse empresarial e o crescimento das pesquisas envolvendo o tema. Para Leite (2009) logística reversa é a área da logística que planeja, opera e controla o fluxo e as informações logísticas, do retorno dos bens de pós-venda e de pós-consumo ao ciclo de negócios ou ao ciclo produtivo, por meio dos canais de distribuição reversos, agregando valor econômico, ecológico, legal, logístico, de imagem corporativa, entre outros. 
A logística reversa pode ser entendida como complementar a logística empresarial, levando em consideração que a última tem o papel de levar o produto do fornecedor até os clientes intermediários ou finais, realizando o fluxo direto e a outra de completar o ciclo, trazendo produtos utilizados ou não de volta ao ponto de origem, para a partir daí destiná-lo de forma correta (LACERDA, 2002). Essa etapa é executada por meio dos Canais de Distribuição Reversos.

É bastante comum ouvir a respeito dos canais de distribuição diretos no processo logístico de uma organização, é através desses canais que é feita toda a comercialização e entrega de produtos ao cliente final. No entanto, esses canais não se responsabilizam pelo retorno dos produtos fabricados a empresa de origem, deixando em aberto essa etapa complementar da logística que é responsável pelo retorno de produtos, componentes, resíduos e embalagens que estão no mercado.

Nesse contexto surgem os Canais de Distribuição Reversos (CDRs) que representam todas as etapas ou meios necessários para o retorno dos produtos comercializados, oriundos de erros de emissão do pedido, defeitos de fabricação, prazo de validade vencido, devoluções, reaproveitamento de embalagens, ciclo de vida útil encerrado, entre outros.

Segundo Leite (2003), CDRs são as etapas, formas e meios em que uma parcela dos produtos comercializados, com pouco uso após a venda, com ciclo de vida ampliado ou depois de extinta a sua vida útil, retorna ao ciclo produtivo ou de negócios, podendo assim agregar valor através de seu reaproveitamento. Os CDRs são divididos em duas categorias distintas: pós-venda (CDR-PV) são constituídos pelas diversas formas e possibilidades de retorno de uma parcela e produtos, com pouco ou nenhum uso, fazendo o sentido inverso, do consumidor ao varejista ou fabricante, do varejista ao fabricante; pós-consumo (CDR-PC) são constituídos pelo fluxo reverso de uma parcela de produtos e de materiais constituintes originados no descarte dos produtos, após finalizada sua utilidade original, retornam ao ciclo produtivo de alguma maneira (LEITE, 2009, p.8). O autor ainda distingue em três os subsistemas reversos que são: os canais de reuso, de remanufatura e de reciclagem, existindo ainda a possibilidade desses produtos irem para destinação final, seguras e controladas, isentando o meio ambiente da poluição, ou não seguras, provocando impactos ao meio ambiente.

Os canais reversos de reuso são definidos como aqueles que se tem a extensão do uso de um produto de pós-consumo ou de seu componente, com a mesma função para a qual foi originalmente concebido, ou seja, sem nenhum tipo de remanufatura, assim, tornam importantes na medida em que reduzem a necessidade de exploração de recursos que seriam necessários para a produção de novos produtos. Os de remanufatura constitui um canal reverso no qual os produtos podem ser reaproveitados em suas partes essenciais, mediante a substituição de alguns componentes complementares, reconstituindo-se um produto com a mesma finalidade e natureza do original. Já a reciclagem é o canal reverso de revalorização, no qual os materiais constituintes dos materiais 
descartados são extraídos, transformando-se em matéria-prima secundária ou reciclados para que sejam incorporados ao sistema produtivo para fabricação de novos produtos. Além desses canais, ainda tem-se a disposição final, entendida como o último local de destino para o qual são enviados produtos, materiais e resíduos em geral sem condições de revalorização (LEITE, 2009).

Diante do exposto, fica evidente a importância da logística reversa, onde as empresas estão buscando alinhar a logística reversa as suas estratégias, na busca de obter vantagem competitiva, motivadas por questões econômicas, ecológicas, adequação legal ou de imagem. Nesse processo, a redução dos custos de produção através da matéria-prima reciclada pode ser uma fonte de vantagem competitiva que impulsiona organizações na adoção dessa prática sustentável, conforme exposto na sequência.

\subsection{Logística reversa e a reducão de custos}

Um dos grandes desafios das organizações no cenário atual diz respeito à redução dos custos de produção, e consequentemente no aumento dos lucros, visando assim se manterem competitivas no mercado. Essa situação é creditada principalmente a grande exigência do mercado consumidor, que busca produtos com qualidade e preços competitivos. E a oportunidade pode estar nos canais reversos de pós-consumo

O objetivo econômico na logística reversa de pós-consumo visa resultados financeiros que são possíveis através de economias obtidas em operações industriais com o aproveitamento de matérias primas secundárias oriundas dos canais reversos de reciclagem (LEITE, 2003).

Empresas estão sendo atraídas pela possibilidade de redução de custos através dos canais reversos, adquirindo matérias-primas secundárias a preços inferiores do que matérias primas virgens ou primárias. Figueiredo et al (2003), considera a redução de custos como importante justificativa para que as empresas tomem iniciativas relacionadas à logística reversa, uma vez que economias com a utilização de embalagens retornáveis ou com o reaproveitamento de materiais para a produção têm trazido ganhos que estimulam cada vez mais novas iniciativas.

A gestão dos custos vem tomando um papel cada vez mais importante no meio empresarial, em sumo ela é voltada para a formação de preços, utilização de capacidade, análises entre produzir ou comprar, introdução ou redirecionamento de produtos e avaliação de iniciativas orientadas ao cliente. A gestão dos custos fornece aos gerentes das demais áreas da organização informações importantes sobre os custos de suas respectivas atividades, dando auxilio essencial para a tomada de decisão.

Para verificar a possibilidade de redução de custos através dos canais reversos, é de essencial importância a utilização de um sistema de custeio adequado e que permita essa 
mensuração. De acordo com (MARTINS, 2008) um sistema de custeio pode ser entendido como a forma de apropriação dos custos de uma atividade ou empresa aos seus produtos.

Dentre os principais sistemas de custeio encontrados na literatura atual, que são: por Absorção, pleno, ABC e variável. O custeio por absorção utiliza todos os custos fixos ou variáveis para apuração do custo dos produtos; o custeio variável utiliza-se apenas os custos diretos e variáveis, fazendo uso de rateios arbitrários para os custos indiretos; o custeio pleno consiste no rateio dos custos de produção e também de todas as despesas da empresa. O sistema de custeio que mais viabiliza a execução deste trabalho é o método de Custeio Baseado em Atividades (ABC), pelo fato de sua metodologia facilitar a análise dos custos relacionados às atividades mais relevantes no consumo de recursos da organização.

O custeio $\mathrm{ABC}$ é uma metodologia desenvolvida em meados da década de 1980 pelos professores norte-americanos Robert Caplan e Robin Cooper da Universidade de Harvard. O método $\mathrm{ABC}$ consiste em rastrear os gastos de uma empresa para analisar e monitorar as inúmeras direções de consumo seguidas dos recursos diretamente identificáveis com suas atividades mais relevantes e destas para os produtos ou serviços (GARRISON e NOREEN, 1999).

Segundo Martins (2008) o Custeio Baseado em Atividades é uma metodologia de custeio que procura reduzir sensivelmente as distorções provocadas pelo rateio arbitrário dos custos indiretos. Este sistema tem como fundamento básico a busca do princípio da causa, ou seja, procura identificar de forma clara, por meio de rastreamento, o agente causador do custo, para lhe imputar o valor.

Bornia (2008) apud Lima et al (2010) diz que a ideia do custeio ABC é assumir os custos das várias atividades da organização e compreender seu comportamento através de bases que representem a relação entre os produtos e essas atividades. Desta forma, pode-se dizer que o ABC propõe que os custos sejam atribuídos às atividades e não aos produtos.

Assim, as atividades consomem recursos e os produtos/serviços consomem atividades. Os custos indiretos podem ser alocados aos produtos e serviços em duas etapas, a primeira é quando os custos dos recursos são transferidos para as atividades com base nos direcionadores de recursos e a segunda etapa ocorre quando os custos das atividades são transferidos para os produtos e serviços tomando por base o consumo das atividades para parte destes.

De acordo com Bornia (2008) apud Lima et al (2010), para que o sistema ABC seja implantado devem ser seguidos os seguintes passos:

- Mapeamento das atividades: Fazer um levantamento e identificar todas as atividades realizadas pela a empresa. 
- Alocação dos custos às atividades: Essa é a primeira distribuição dos custos, a qual deve apresentar o consumo do recurso pela atividade, ou seja, atribui-se todos os custos gerados pela atividade correspondente;

- Redistribuir os custos das atividades indiretas as diretas: com base nos direcionadores de custos (causadores dos custos das atividades) é feita a segunda distribuição. Dessa forma, distribuem-se os custos das atividades aos produtos, rateando conforme o consumo de cada atividade por produto;

- Calcular os custos dos produtos/serviços: nessa etapa tem-se o custo individual de cada produto ou serviço. Os custos diferem para cada objeto de custos tendo em vista que há uma diferenciação quanto ao uso das atividades indiretas.

Lima et al (2010) aplicou o custeio ABC para mensurar os custos da logística reversa de pós-venda numa empresa de artigos esportivos no estado da Paraíba. O processo começa com o contato realizado por algum consumidor pelo Serviço de Atendimento ao Consumidor (SAC), devido a algum tipo de insatisfação com o produto adquirido, logo em seguida o produto é coletado e analisado, caso a reclamação proceda outro produto é enviado ao cliente, caso a reclamação não proceda, o mesmo produto é devolvido num prazo de 30 dias, conforme dita o Código de Defesa do Consumidor (CDC). Após implantar o custeio ABC seguindo os passos citados, foi possível encontrar o custo total do serviço para as reclamações que precedem e para as que não procedem.

Considerando que a implementação da logística reversa de pós-consumo tem como estratégia econômica comparar o valor da economia reversa de bens produzidos com matéria-prima primária e secundária (LEITE, 2009). Surge à necessidade de analisar qual será mais vantajoso economicamente, utilizar da compra da matéria-prima virgem ou da matéria-prima secundária, oriunda da reciclagem.

Dentre os materiais mais comuns que são reciclados, que são vidro, plástico, metais e papel, o plástico aparece como um dos destaques, por sua flexibilidade e aplicabilidade, nos mais diversos setores da indústria, mas também é visto por um lado negativo, já que é um dos mais agride o meio ambiente.

\subsection{Setor de plástico}

O plástico é um dos materiais mais usados na atualidade em todo mundo, utilizados praticamente em quase tudo, como por exemplo, em materiais eletrônicos, veículos automotores, utensílios do lar, nas mais diversas formas de embalagens, entre outros. De acordo com a ABIPLAST são materiais sintéticos ou derivados de substância naturais, geralmente orgânicas, obtidas, atualmente, em sua maioria, a partir dos derivados de petróleo. As principais características 
desse material são o baixo custo, alta resistência, flexibilidade na variação de formas e cores, alem de ser quase sempre um material reciclável.

Por todas essas vantagens, o plástico é utilizado em praticamente todos os setores da indústria, se destacando por sua versatilidade. Segundo Pereira et al (2011) o plástico é um material a base de polímeros que são classificados em dois grandes grupos quando sofrem processos de aumento de temperatura, que são: Termoplásticos e Termorrígidos.

Os termoplásticos são aqueles que amolecem ao serem aquecidos, podendo ser moldados e quando resfriados endurecem podendo tomar uma nova forma, esse processo podendo ser repetido diversas vezes, os termoplásticos correspondem à maioria dos produtos consumidos, com um total de $80 \%$ de todos os produtos feitos à base de plástico (FILHO, 2006). Já os termorrígidos são polímeros que sofrerão reações químicas por aquecimento, transformando-se em substâncias insolúveis e infusíveis, não oferecendo assim, condições de reciclagem.

De acordo com o Instituto Socioambiental dos Plásticos (PLASTIVIDA) os materiais plásticos são utilizados em quase todos os setores da economia, tais como: construção civil, agrícola, de calçados, móveis, alimentos, têxtil, lazer, telecomunicações, eletroeletrônicos, automobilísticos, médico-hospitalares e distribuição de energia.

A ABIPLAST (2011) estima que este setor seja composto por mais de 11 mil empresas instaladas em todo o território nacional, empregando mais de 350 mil pessoas e esse número de empregos cresce numa taxa de $6 \%$ a.a e que o consumo anual médio per capta de plástico no Brasil é de $30 \mathrm{~kg} /$ habitante. Atualmente, as indústrias de transformação vêm utilizando uma grande quantidade de termoplásticos como matéria prima, os principais são o polipropileno (PP), o policloreto de vinila (PVC), o polietileno de baixa densidade (PEBD), o polietileno de alta densidade (PEAD) e o polietileno tereftalato (PET).

Leite (2009) diz que existe um expressivo crescimento do setor de plásticos no Brasil nos últimos anos por meio da forte introdução dos materiais plásticos nos produtos atuais, assim como em todo o planeta, o que por outro lado é motivo de extrema preocupação por parte dos ambientalistas, por conta dos índices de reciclagens do setor, que ainda são considerados baixos. No entanto, de acordo com Motta (2010) a reciclagem contribui para reduzir a quantidade de material descartado no meio ambiente, pois o utiliza como matéria-prima para produzir novos materiais plásticos.

Considerando o contexto da logística reversa de pós-consumo, o canal reverso da reciclagem apesar de ainda não ter a atenção e os investimentos necessários por parte dos governos, é de fundamental importância na prevenção, redução e no controle dos resíduos descartados e consequentemente dessa agressão histórica ao meio ambiente, seja no solo, no ar ou na água. Diante dos benefícios evidenciados pela utilização da logística reversa, especialmente, pela utilização do 
canal reverso de reciclagem, que o presente trabalho direciona seu foco para analisar os custos do canal reverso de reciclagem, estabalecendo uma comparação com os custos do canal tradicional ou direto da fabricação de um produto numa empresa de plático localizada em Campina Grande.

\section{Aspectos metodológicos}

A pesquisa consiste em um estudo de caso realizado numa empresa do setor de plástico localizada em Campina Grande-PB. A empresa fabrica produtos oriundos de matéria-prima virgem (garrafões de 201 para envasamento de água mineral), ao mesmo tempo, atua n a fabricação de produtos como: hastes para bandeira, caixas de óculos, cercas elétrica, pés de estofado, entre outros, todos com material reciclado.

A pesquisa é descritiva, pois buscou descrever o canal de distribuição reverso de reciclagem da empresa e a participação da empresa em um canal de reciclagem de plásticos diversos de pósconsumo. É exploratória, por gerar novos conhecimentos em relação à logística reversa e gestão de custos, mediante a aplicação do método de custeio ABC, tema ainda pouco explorado. A Pesquisa é qualitativa e quantitativa, pois quanto à natureza dos dados é quantitativa, porém quanto à análise é qualitativa.

Ressalta-se que para o desenvolvimento do estudo na empresa tomou-se como base o Modelo de Lima et al (2010) onde o mesmo utiliza o método ABC para mensurar os custos das operações logísticas de pós-venda numa empresa de artigos esportivos.

A técnica utilizada para coleta de dados foi entrevista mediante um roteiro dividido em 2 partes: a parte 1 buscou levantar informações sobre a caracterização da empresa e do canal reverso de reciclagem; a parte 2 buscou quantificar os custos das atividades do processo direto e reverso de reciclagem da empresa, através dos itens de custos e direcionadores de recursos, conforme a lógica do método de custeio ABC. Foram utilizados também arquivos da empresa e a observação direta através de visitas. A coleta dos dados foi realizada no mês de Abril de 2013, a partir das visitas à empresa.

A análise dos dados foi feito de forma qualitativa comparando os resultados obtidos com a literatura estudada. Para a operacionalização dos resultados utilizou-se a sequência de etapas de método $\mathrm{ABC}$, com o diferencial de aplicar às atividades reversas de reciclagem, sendo: mapeamento das atividades para fabricação dos produtos reciclados; definição dos direcionadores de recursos, cujos dados foram informados pela empresa. A partir dos custos levantados, os mesmo foram alocados às atividades reversas da empresa, permitindo a comparação utilizar material reciclado ou material virgem comprado direto aos fornecedores. 


\section{Resultados}

\subsection{Caracterização da empresa}

A empresa em estudo é de pequeno porte e iniciou suas atividades no ano de 1993 apenas com a produção de tampas de garrafões para envasamento de água mineral. Só no ao de 2005 começou a produzir os garrafões de 201 de água mineral, obtendo significativa vantagem competitiva, uma vez que esse produto ainda não era fabricado na Paraíba, sendo atendida pelos Estados do Rio Grande do Norte e de Pernambuco. Percebendo essa oportunidade, a empresa investiu nesse produto que hoje é principal da empresa.

Esses garrafões até então não possuíam prazo de validade, porem a partir de setembro de 2009, o Departamento Nacional de Produção Mineral (DNPM) estabeleceu um prazo máximo de uso de três anos, e também estabeleceu que os produtos que já estava no mercado por um prazo superior a esse, deveriam ser retirados. Na época, a lei gerou polêmica e discussões, pois, de certa forma essa regra iria aumentar os custos para os dessalinalizadores, distribuidores e clientes. Com essa nova regra os fabricantes desses garrafões foram os grandes beneficiados, pois viram um grande crescimento nas vendas, vale salientar que as exigências quanto à fabricação também aumentaram e, consequentemente, a qualidade do produto melhorou.

Com o retorno desses produtos, após o prazo de validade, a empresa em estudo percebeu uma grande oportunidade de ganhos econômicos através da redução de custos através da utilização desses materiais como matéria-prima. A partir daí, a empresa vem utilizando o canal reverso de reciclagem para retorno e utilização desses materiais na fabricação de novos produtos, entre eles as caixas ou estojos para óculos.

A cadeia reversa da empresa em estudo se inicia com a compra de plásticos diversos e com o retorno de garrafões de 201 vencidos ou danificados, em seguida esse material passa por alguns processos descritos na Figura 1, deixando-os em condições de serem utilizados na produção de novos produtos, considerado no presente estudo, apenas as caixinhas recicladas para óculos. 
Figura 1- Canal de reciclagem da empresa

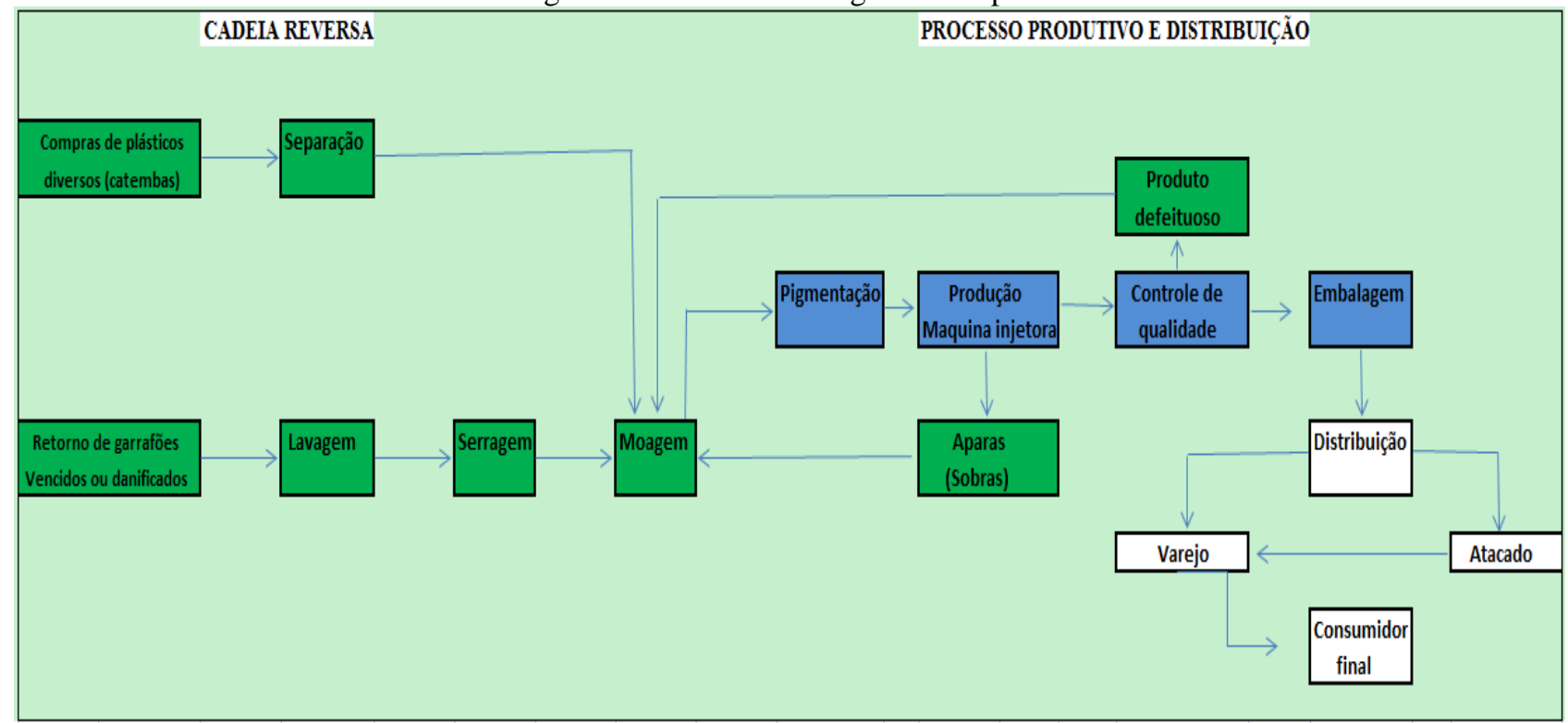

Fonte: Autoria própria, 2013

O processo reverso de reciclagem começa com a aquisição de materiais secundários ou reciclados de pós-consumo, passando pelo processo de recuperação desse material, inclusão no processo produtivo e distribuição até chegar ao consumidor final.

O retorno desses garrafões é feito através dos distribuidores e dessalinalizadores à empresa em estudo, que oferece 1 garrafão novo para cada 5 vencidos ou danificados, o que resulta em vantagem para ambas as partes e, principalmente, para o meio ambiente. Após chegada dos garrafões à empresa, os mesmos são lavados, serrados e moídos para que possam ser inseridos no processo produtivo. O material plástico oriundo desses garrafões é o Polipropileno, um dos principais termoplásticos usados no setor como já foi mostrado.

Além desse material, também são comprados plásticos diversos conhecidos no meio como 'catembas', que são baldes, potes de margarina, de xampu, alguns tipos de garrafas, entre outros, materiais estes que são adquiridos junto a sucateiros do município, esses plásticos diversos são separados e moídos, ficando aptos para serem inseridos no processo produtivo.

Com os materiais secundários prontos, inicia-se o processo produtivo das caixinhas de óculos, a primeira etapa é a pigmentação, que consiste no acréscimo de um tipo de tinta aos materiais, que será responsável pela coloração do produto. Após essa etapa os materiais já pigmentados, são colocados numa máquina injetora que fará a moldagem da caixinha. Concluída essa fase, os produtos são destinados ao controle de qualidade para que possam ser avaliados de acordo com padrões de qualidade estabelecidos pela empresa. Caso estejam de acordo com as normas de qualidade, são levados para o setor de embalagem, se apresentem algum defeito são reinseridos na etapa de moagem e poderão retornar ao processo produtivo. 
Com o produto finalizado, ele seguirá para o setor de embalagens, para depois serem estocadas, e posteriormente comercializadas com atacadistas e varejistas.

A utilização desse material reciclado na fabricação de caixas de óculos faz com que a empresa tenha uma significativa abrangência no mercado local e Estados vizinhos, onde a mesma afirma que é uma estratégia que resulta em redução de custos. Diante dessa percepção, torna-se relevante mensurar os custos da operação logística reversa de reciclagem e comparar com a utilização do material virgem na fabricação desses produtos.

\subsection{Mensurando os custos da operação logística reversa de pós-consumo}

Como já foi visto o retorno dos produtos ao processo produtivo através dos canais de distribuição reversos pode possibilitar ganhos econômicos para a empresa, como nos canais de reciclagem, que reaproveitam materiais usados como matéria-prima para novos produtos. No entanto, para que seja possível afirmar que realmente é viável ou não para a empresa é de grande importância que sejam identificados todos os custos relacionados a cada atividade do processo logístico reverso, já que esses materiais precisam passar por alguns processos de recuperação que consumem custos para a partir daí, poderem ser inseridos novamente no processo produtivo para produção das caixinhas de óculos.

\subsubsection{Aplicando o método de custeio ABC na operação de logística reversa da empresa}

Foi necessário identificar e analisar os custos relacionados às atividades que mais impactam no consumo de recursos da empresa estudada, para que a partir daí se pudesse implementar as etapas desse método. Os dados fornecidos pela empresa para mensuração dos custos da cadeia reversa são referentes ao mês de fevereiro de 2013, no qual a produção foi de 200.000 unidades de caixas de óculos. Sendo assim foram identificados os itens de custos diretos e indiretos da operação e seus respectivos valores, conforme Tabela 1.

Tabela 1- Custos diretos do canal reverso da empresa

\begin{tabular}{c|c|c|c}
\hline ATIVIDADE & ITENS DE CUSTO & QUANTIDADE & VALOR R\$ \\
\hline \multirow{2}{*}{ Compras } & Plásticos diversos & $2.000 \mathrm{Kg}$ & $4.000,00$ \\
\cline { 2 - 4 } & ICMS & $17 \%$ do valor dos plásticos & 680,00 \\
\hline \multirow{2}{*}{ Retorno } & Garrafões vencidos & $17 \%$ do valor dos garrafões & $2.358,00$ \\
\cline { 2 - 4 } & ICMS & $\mathrm{R} \$ 0,07$ por Kg & 140,00 \\
\hline \multirow{2}{*}{ Leparação } & Mão de Obra & $\mathrm{R} \$ 0,08$ por $\mathrm{Kg}$ & 640,00 \\
\cline { 2 - 4 } & Mão de Obra & $165 \mathrm{~m} 3$ & 540,00 \\
\cline { 2 - 4 } & Água & Suficiente para o mês & 200,00 \\
\hline \multirow{2}{*}{ Serragem } & Material de limpeza & $\mathrm{R} \$ 0,08$ por Kg & 640,00 \\
\cline { 2 - 4 } & Mão de Obra & $\mathrm{KWH} /$ Tempo de operação & 300,00 \\
\hline \multirow{2}{*}{ Moagem } & Energia Elétrica & $\mathrm{R} \$ 0,07$ por Kg & 700,00 \\
\cline { 2 - 4 } & Mão de Obra & $\mathrm{KWH} / \mathrm{Tempo}$ de operação & $1.230,00$ \\
\hline
\end{tabular}

Fonte: Autoria própria (2013) 
Para que fosse possível fabricar 200.000 unidades de caixinhas de óculos, foram necessários $10.000 \mathrm{Kg}$ de matéria-prima reciclada na proporção de $20 \%$ para plásticos diversos (catembas) e $80 \%$ de polipropileno reciclado dos garrafões. Sendo assim, foram adquiridos $2.000 \mathrm{Kg}$ de plásticos diversos como baldes, potes de xampu, de margarina entre outros. O valor do quilo desse material é de $\mathrm{R} \$ 2,00$, totalizando $\mathrm{R} \$ 4.000,00$. No ato da compra desse material, é emitida uma nota fiscal avulsa de Imposto Sobre Circulação de Mercadorias e Serviços (ICMS) junto à recebedoria de rendas, a alíquota de ICMS cobrada no estado da Paraíba é de $17 \%$ o que totalizou um imposto não recuperável de $\mathrm{R} \$ 680,00$.

Foram retornados também cerca de $8.000 \mathrm{Kg}$ de garrafões vencidos ou danificados. A Empresa negocia com os distribuidores 1 garrafão novo para cada 5 sem condições de uso, levando em consideração que o preço do garrafão novo é de $\mathrm{R} \$ 6,50$, o custo do valor unitário do garrafão em desuso é de R\$ 1,30 para a Empresa, tendo em vista que o peso do garrafão que é de $750 \mathrm{~g}$. Foram adquiridos cerca de 10.667 garrafões, totalizando R $\$ 13.867,00$, somado ao ICMS que foi de $\mathrm{R} \$ 2.358,00$.

Na etapa de separação, são incluídos apenas os plásticos diversos, que já os garrafões compõem apenas um tipo de material, sendo desnecessária essa etapa. Levando em consideração a estimativa do responsável, o custo de mão de obra dessa atividade é de aproximadamente $\mathrm{R}$ 7 centavos por quilo do material, o que totalizou $\mathrm{R} \$ 140,00$.

A lavagem dos materiais é aplicada apenas aos garrafões retornados já que os plásticos diversos já chegam limpos a empresa. A mão de obra estimada pelo responsável da área é de $\mathrm{R} \$ 8$ centavos por quilo do material, totalizando assim $\mathrm{R} \$ 640,00$. Foram consumidos cerca de $165 \mathrm{~m} 3$ de água nessa atividade, a um preço de $\mathrm{R} \$ 3,28$ por $\mathrm{m} 3$, resultou em $\mathrm{R} \$ 640,00$. Já os materiais de limpeza utilizados no mês referência custaram cerca de $\mathrm{R} \$ 200,00$. Os materiais comprados são detergentes, buchas, cloro, entre outros. Não foi verificado nenhum programa eficiente de uso e descarte dessa água, que feito da forma que é se configura como outro problema ambiental.

Na serragem também só são inseridos os $8.000 \mathrm{Kg}$ de garrafões, levando por base mais uma vez a estimativa do responsável pelo setor a mão de obra foi de $\mathrm{R} \$ 8$ centavos por quilo do material, dessa forma o custo dessa atividade foi de $\mathrm{R} \$ 640,00$. O custo com a energia elétrica foi definido através de alocação direta, tomando por base a máquina executora, que no mês base foi de $\mathrm{R} \$$ 300,00 .

A última etapa da cadeia reversa antes de chegar ao processo produtivo, foi a da moagem, em que tanto os plásticos diversos quanto os garrafões retornados passam por ela. $\mathrm{O}$ valor da mão de obra estimada é de R\$ 7 centavos por Quilo do material processado, totalizando 700,00. O custo com a energia elétrica também foi calculado através de alocação direta, baseado na máquina executora dessa etapa, que no mês de fevereiro foi de $\mathrm{R} \$ 1.200,00$. 


\subsubsection{Etapas de aplicação}

A Aplicação do método ABC seguiu as etapas mostradas na literatura: mapeamento das atividades, alocação dos custos às atividades e cálculo dos custos do produto.

Quanto ao mapeamento das atividades, foram listadas as atividades que compõem o processo de logística reversa de pós-consumo da empresa na Figura 2.

Figura 2 - Cadeia reversa de reciclagem da empresa

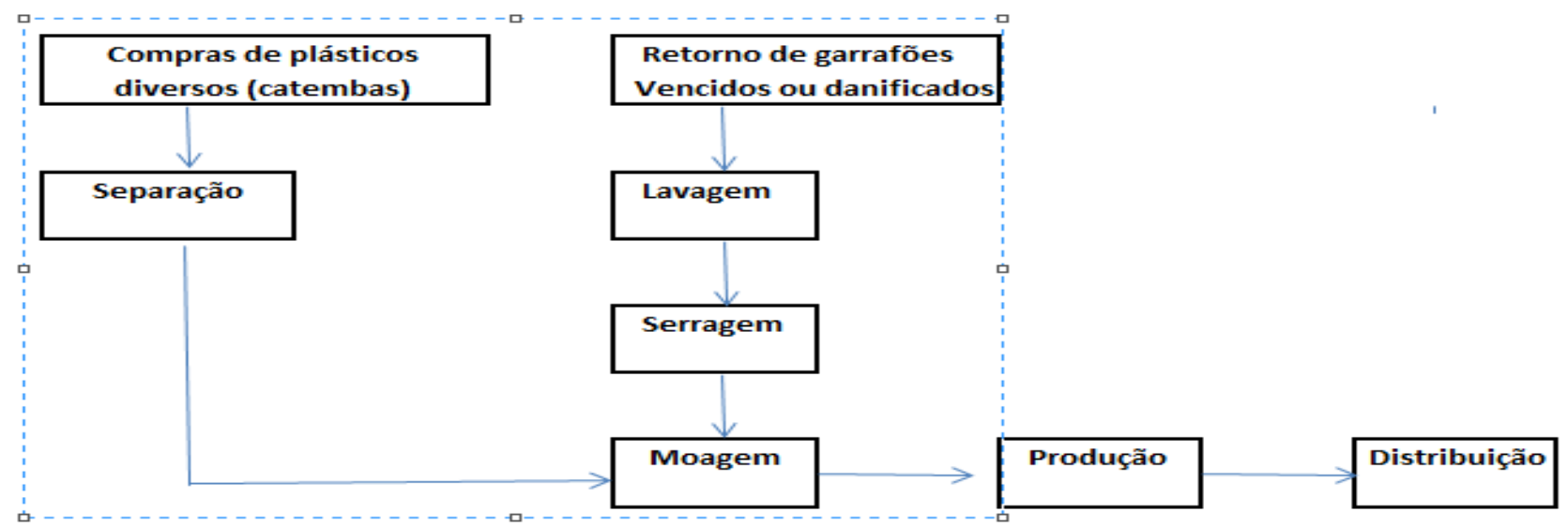

Fonte: Autoria própria, 2013

Com o mapeamento da cadeia reversa foram identificadas as atividades, os recursos consumidos por elas e também os direcionadores de recursos, conforme Quadro 1.

Quadro 2 - Mapeamento das atividades, itens de custos e direcionadores de recursos

\begin{tabular}{|c|c|c|}
\hline ATIVIDADES & ITENS DE CUSTO & DIRECIONADORES DE RECURSOS \\
\hline \multirow[t]{2}{*}{ Compras } & Material (Plásticos Diversos) & Quant. Kg / Valor \\
\hline & ICMS & Alíquota de $17 \%$ (Paraíba) \\
\hline \multirow[t]{2}{*}{ Retorno } & Garrafões vencidos ou danificados & Quant. Kg / Valor \\
\hline & ICMS & Alíquota de 17\% (Paraíba) \\
\hline Separação & Mão de Obra & Estimativa/ valor por quilo do material Separado \\
\hline \multirow[t]{3}{*}{ Lavagem } & Mão de Obra & $\begin{array}{l}\text { Estimativa/ valor por quilo } \\
\text { do material lavado }\end{array}$ \\
\hline & Água & Valor/Consumo m3 \\
\hline & Material de Limpeza & Valor \\
\hline \multirow[t]{4}{*}{ Serragem } & Mão de Obra & $\begin{array}{c}\text { Estimativa/ valor por quilo do material } \\
\text { serrado }\end{array}$ \\
\hline & Energia elétrica & $\begin{array}{l}\text { Valor Kilowatt hora/ tempo mensal de } \\
\text { processamento }\end{array}$ \\
\hline & Manutenção & Ordem de manutenção \\
\hline & Depreciação & Valor da máquina/vida útil/período \\
\hline \multirow[t]{4}{*}{ Moagem } & Mão de Obra & Estimativa/ valor por quilo do material moído \\
\hline & Energia elétrica & $\begin{array}{l}\text { Valor Kilowatt hora/tempo } \\
\text { mensal de processamento }\end{array}$ \\
\hline & Manutenção & Ordem de manutenção \\
\hline & Depreciação & Valor da máquina/vida útil/período \\
\hline
\end{tabular}

Fonte: Autoria própria, 2013

É importante ressaltar que são itens de custo: mão de obra presente nas atividades de separação, lavagem, serragem e moagem, o direcionador de custos mais apropriado para ambas 
seria valor da hora trabalhada/ tempo de processamento. Não foi possível usar esse direcionador pelo fato dessas atividades serem esporádicas, sem produção fixa diária e sem um número fixo de funcionários, que variam de acordo com a quantidade de materiais que chega à empresa.

Quanto à alocação dos custos dos recursos às atividades, após ter sido identificados os itens de custos e seus valores, os mesmos foram atribuídos às atividades, de acordo com a utilização dos recursos. Ou seja, foram alocados os custos diretos consumidos pelas atividades diretas e também foram alocados os custos indiretos da atividade de moagem, conforme Quadro 2.

\begin{tabular}{|c|c|c|c|c|c|c|}
\hline ATIVIDADES & Compras & Retorno & Separação & Lavagem & Serragem & Moagem \\
\hline ITENS DE CUSTOS & & & & & & \\
\hline \multicolumn{7}{|c|}{ Alocação dos custos diratos as atividades } \\
\hline \multicolumn{7}{|l|}{ Plásticos Diversos } \\
\hline ICMS & 0,0034 & & & & & \\
\hline \multicolumn{7}{|l|}{ Garrafôes Vencidos } \\
\hline ICMS & & 0,012 & & & & \\
\hline Mẫo de Obra & & & 0,0007 & & & \\
\hline Măo de Obra & & & & 0,0032 & & \\
\hline Consumo de água & & & & 0,0027 & & \\
\hline Material de Limpeza & & & & 0,001 & & \\
\hline Măo de Obra & & & & & 0,0032 & \\
\hline \multicolumn{7}{|l|}{ Energia Elétrica } \\
\hline Mẵo de Obra & & & & & & 0,0035 \\
\hline Energia Elétrica & & & & & 0,0015 & 0,0061 \\
\hline \multicolumn{7}{|c|}{ Alocação dos custos indiretos as atividades } \\
\hline Depreciação & & & & & 0.000333 & 0,0008333 \\
\hline Manutenção & & & & & 0,0015 & 0,0015 \\
\hline Custo Total & 0,0234 & 0,082 & 0,0007 & 0,0069 & 0,0062 & 0,0119333 \\
\hline
\end{tabular}

Fonte: Autoria própria, 2013

Para que os custos tornassem unitários, todos os valores dos itens de custos e também os custos indiretos foram divididos por 200.000 que corresponde à quantidade de caixinhas de óculos produzida no mês de fevereiro deste ano, período base desse estudo. Os custos indiretos de depreciação e de manutenção são referentes às atividades de serragem e moagem e suas respectivas máquinas. A depreciação foi calculada através dos valores que essas máquinas foram adquiridas que são $\mathrm{R} \$$ 8.000,00 e R \$ 20.000,00 e da taxa dedutível estabelecida pela Receita Federal que para máquinas é de $10 \%$ a.a. Já a manutenção se refere a uma ordem mensal para cada máquina, somada a alguns produtos como óleos lubrificantes que são necessários para seu funcionamento.

Em relação à redistribuição dos custos das atividades indiretas às diretas tomando como base o mapeamento do processo e as informações, não foi identificada nenhuma atividade indireta, dessa forma não foi possível redistribuir os custos das atividades indiretas as diretas. 
A partir das etapas expostas, torna-se possível calcular o custo da matéria prima reciclada, através do custo das atividades do canal reverso de reciclagem, conforme Tabela 2.

Tabela 2 - Custos das atividades do material reciclado

\begin{tabular}{c|c|c}
\hline ATIVIDADES & CAIXA DE ÓCULOS RECICLADA & PARTICIPAÇÃO (\%) \\
\hline Compras & $\mathrm{R} \$ 0,02340$ & $17,80 \%$ \\
\hline Retorno & $\mathrm{R} \$ 0,08200$ & $62,37 \%$ \\
\hline Separação & $\mathrm{R} \$ 0,00070$ & $0,53 \%$ \\
\hline Lavagem & $\mathrm{R} \$ 0,00690$ & $5,25 \%$ \\
\hline Serragem & $\mathrm{R} \$ 0,00650$ & $4,97 \%$ \\
\hline Moagem & $\mathrm{R} \$ 0,01193$ & $9,08 \%$ \\
\hline CUSTO TOTAL & $\mathbf{R} \mathbf{0 , 1 3 1 5}$ & $\mathbf{1 0 0 \%}$ \\
\hline
\end{tabular}

Fonte: autoria própria (2013)

O custo total com a aquisição da matéria prima e das demais atividades de recuperação desse material fica de aproximadamente $\mathrm{R} \$ 0,13$ centavos por unidade produzida. Vale reafirmar que esse é o custo com a matéria prima reciclada, ou seja, antes de entrar no processo produtivo. Dessa forma, conclui-se que a atividade de compras consumiu $17,80 \%$ do custo da cadeia reversa de reciclagem, já o atividade de retorno dos garrafões consumiu $62,37 \%$, o processo de separação consumiu apenas $0,53 \%$ do custo total, enquanto a lavagem foi responsável por 5,25\%, serragem por $4,97 \%$ e moagem por $9,08 \%$ do custo total da matéria prima reciclada.

Para efeito comparativo, um dos objetivos desse estudo é necessário calcular qual seria o custo unitário caso fosse usada matéria prima virgem na produção das caixinhas de óculos, e a partir daí afirmar qual é mais economicamente vantajoso para a Empresa. Sendo assim, foi feita uma estimativa mostrando o custo da matéria prima virgem.

Levando em consideração a produção do mês de fevereiro de 2013, que foi de 200.000 unidades, seria necessário também de $10.000 \mathrm{Kg}$ de matéria prima virgem, neste caso o polipropileno, a um custo de $\mathrm{R} \$ 7,00$ o quilo, resultando em $\mathrm{R} \$ 70.000,00$. Como a Empresa já compra esse material virgem para a fabricação dos garrafões de 201, já é sabido que o transporte e o descarregamento desse material é inteiramente responsabilidade do fornecedor, se tornando um custo a menos para a Empresa. O que é pago no ato da compra é a diferença de alíquota de ICMS, já que o fornecedor é do Estado de Pernambuco, cujo valor é de $12 \%$ e na Paraíba é de 17\%, seria pago uma alíquota de 5\% de ICMS, totalizando R $\$ 3.500,00$.

Dessa maneira, o custo total com material virgem seria de $73.500,00$, dividindo esse valor pela quantidade produzida de 200.000,00. O custo unitário com o material virgem seria de aproximadamente $\mathrm{R} \$ 37$ centavos.

$\mathrm{Na}$ comparação do material reciclado com o material virgem foi verificado que o custo unitário com da matéria prima reciclada é de aproximadamente R\$ 13 centavos, enquanto da matéria prima virgem seria de $\mathrm{R} \$ 37$ centavos, uma diferença de R 24 centavos por unidade produzida, já que o processo produtivo para ambas é inteiramente o mesmo. O que evidencia que 
mesmo com as atividades de separação, lavagem, serragem e moagem que o material reciclado tem um preço bem inferior ao material virgem que chega a ser aproximadamente $185 \%$ mais caro.

\section{Considerações finais}

No atual momento em que a economia mundial se encontra, fica evidente que a única forma para que as sociedades continuem se desenvolvendo é através de práticas que estejam em harmonia com o meio ambiente, onde é fundamental crescer de forma que não venha a comprometer os recursos naturais que ainda restam, ou seja, deve haver respeito com a natureza.

Como foi visto, o avanço tecnológico permitiu o aumento do número de produtos introduzidos no mercado, aumentando assim o descarte desses produtos e de seus componentes em lugares muitas vezes impróprios. Dessa forma a logística reversa surge como importante ferramenta de combate na tentativa de frear os altos índices de descarte na sociedade, trazendo de volta esses produtos e componentes ao processo produtivo, poupando assim fontes naturais, cada vez mais escassas nos dias de hoje. Mas que, se a empresa não implantar um sistema de gestão ambiental com relação ao consumo eficiente e destinação da água, estará também prejudicando o meio ambiente.

O canal reverso de reciclagem da empresa estudada, apesar de necessitar de alguns ajustes é bem estruturado e hoje abastece cerca de 5 produtos além das caixinhas de óculos, que são: hastes para bandeiras, hastes para cerca elétrica, pés de estofado, cabides expositores e pentes.

Para alcançar o objetivo principal deste trabalho, que foi de identificar e mensurar os custos envolvidos nas atividades do canal reverso de reciclagem foi aplicado o método ABC, que por ser também um sistema de gestão de custos, pode ser implantado com maior ou menor grau de detalhamento, dependendo das necessidades de informações gerenciais para o gestor, o que está intimamente ligado ao ramo de atividade e porte da empresa.

Foi verificado que o custo da matéria prima virgem é quase três vezes maior do que o custo com o material reciclado, mesmo este passando por outras atividades onerosas como separação, lavagem, serragem e moagem, alem dos custos indiretos de depreciação e manutenção. Reforçando ainda mais a ideia que os canais de reciclagem bem estruturados trazem redução significativa de custos com materiais, alem de outros ganhos de imagem corporativa.

A empresa possui um canal de distribuição reverso de reciclagem que condiz com a realidade da empresa, seu porte e o nível de qualidade exigida dos produtos reciclados que são fabricados. Mas no que se referem ao funcionamento da cadeia, algumas medidas poderiam ser aplicadas para melhorar o seu fluxo reverso.

Alguma campanha de marketing orientada a conscientização e importância da coleta domiciliar e seletiva de plásticos e também de outros materiais recicláveis, algo que não é muito 
comum pelo menos aqui no Brasil, essas campanhas poderiam ser aplicadas nos pontos de venda de seus produtos aos distribuidores, o que fortaleceria o interesse da sociedade, dos donos de fontes e dos demais elos da cadeia, sobre essa prática indispensável ao meio ambiente, e ainda traria ganhos de imagem ao vincular a marca a programas de gestão ambiental como este.

Algum sistema informatizado que permita a empresa mensurar a necessidade de materiais, baseado na previsão de demanda, que oscila bastante durante do ano, algo ainda inexistente na empresa.

\begin{abstract}
At an age in which the environmentally correct attitudes are increasingly charged, attitudes that reduce the exploitation of natural resources are increasingly important. In accordance to the issues mentioned above, reverse logistics emerges as an important alternative for enterprises to get advantage on other companies in the market by reducing their costs, while they are part of a series of laws, besides that, these enterprises will be able to make the society pleases through sustainable practices. The paper aims to measure the cost of the reverse channel recycling, establishing a comparison with the costs of the direct channel of manufacturing products in the company in Campina Grande. The research was characterized as descriptive and exploratory by describing the reverse channel recycling practiced in the previously mentioned company and explore a topic not yet researched through qualitative and quantitative analysis. As a method to measure the costs of the activities of the reverse channel recycling company, was taken as the base model of Lima et al (2010), where it uses the ABC costing. The results shows that the reverse channel, even with some costly processes of material recovery, presents a lower cost to the company if compared with the direct channel that uses virgin material. That way, the contribution of this work is to show that the reverse channels may offer benefits for businesses through reduction of costs, reduces the utilization and exploitation of natural resources, reduction of environmental impacts from recycling, new economic prospects for materials considered low economic value.
\end{abstract}

Key-words: reverse logistics; recycling; cost-cutting.

\title{
Referências
}

ABIPLAST: Associação Brasileira da Indústria do Plástico. Estatísticas e Relatórios, 2010. Disponível em: < http://www.abiplast.org.br/>. Acesso em: 10 Fev. 2013.

BALLOU, R. H. Logística Empresarial. São Paulo: Atlas, 1995.

BALLOU, R. H. Gerenciamento da cadeira de suprimentos: planejamento, organização e logística empresarial. Porto Alegre: Bookman, 2001.

CHAVES, G.L.D.; ALCÂNTARA, R.L.C.. Logística reversa: uma análise de sua evolução por meio da revisão de literatura. Disponível em: <HTTP://www.sargas.com.br>. Acesso em: 09 Fev. 2013.

CLM - COUNCIL OF LOGISTICS MANAGEMENT. Reuse And Recycling Reverse Logistics Opportunities. Illinois: Council of Logistics Management, 1993.

BOWERSOX, D.J.; CLOSS D.J. Logística empresarial: o processo de integração da cadeia de suprimento. São Paulo: Atlas, 2011.

CEMPRE. Compromisso Empresarial para reciclagem. O mercado para reciclagem. Disponível em: <http://www.cempre.org.br/ft_plastico.php> Acesso em: 15 de Mar de 2013. 
FIGUEIREDO, K..F.; FLEURY, P.F.; WANKE, P. Logística e Gerenciamento da cadeia de suprimentos:

Planejamento do fluxo de produtos e dos recursos. São Paulo: Atlas, 2003. (Coleção Coppead de Administração).

FILHO, H.M.V. Plástico: descrição e análise do ciclo de reciclagem, 2006. Disponível em: <http://www.nima.pucrio.br/cursos/pdf/043_humberto.pdf>. Acesso em: 29 mar. 2013.

GARRISON, R. H.; NOREEN, E. W. Managerial Accounting. Irwin McGraw Hill, 1999, 923 p.

LACERDA, L. Logística Reversa: uma visão sobre os conceitos básicos e as práticas operacionais. 2002. Disponível em: http://www.sargas.com.br/site/artigos_pdf. Acesso em: 10 Fev. 2013.

LIMA, J. G. SIMOES, A.; LEITE, M.S. Mensuração dos custos em uma operação de logística reversa: o caso de uma empresa de artigos esportivos. ABCustos Associação Brasileira de Custos - v. V, n. 2, mai/ago, 2010. ISSN 19804814 .

LEITE, P.R. Logística reversa: meio ambiente e competitividade. São Paulo: Prentice Hall, 2003.

LEITE, P.R. Logística reversa: meio ambiente e competitividade. São Paulo: Pearson Prentice Hall, 2009.

MARTINS, E. Contabilidade de custos. 9.ed. São Paulo: Atlas, 2008.

MOTTA, D. Brasileiros desenvolvem método inédito para reciclagem de plástico. 2010. Disponível em: <http://www.inovacaotecnologica.com.br/noticias/noticia.php?artigo=metodo-inedito-reciclagemplastico\&id=010125100715>. Acesso em: 19 mar. 2013.

PEREIRA, A.L. et al. Logística Reversa e Sustentabilidade. São Paulo: Cengage Learning, 2011.

PLASTIVIDA. Instituto Socio-Ambiental dos Plástivos. Os plásticos: tipos de plásticos. Disponível em: <http://www.plastivida.org.br/2009/Plasticos_Tipos.aspx>. Acesso em: 22 mar. 2013.

\section{Dados dos autores}

Nome: Júlio Cesar Ramos Loureiro Marinho

Filiação institucional: Universidade Federal de Campina Grande

e-mail: julio13@hotmail.com

Nome: Maria de Fátima Martins

Filiação institucional: Universidade Federal de Campina Grande - UFCG

Função/cargo: Professora

Endereço: Maria Aparecida Carneiro, 280 - Bairro Catolé - Campina Grande-PB. CEP: 58.410-367 e-mail: fatimamartins@pq.cnpq.br

Submetido em: 04/10/2014

Aceito em: 17/12/2014 